\title{
FARM HAZARDS AND THE HEALTH AND SAFETY IN EMPLOYMENT ACT
}

\author{
Jaron Stallard
}

Farm injury statistics are at an undesirable level in New Zealand. One supposed mechanism for reducing farm injuries is compliance with the provisions of the Health and Safety in Employment Act (the HSE Act). However, this paper argues that the HSE Act is not achieving its objectives in farming, and is creating negative consequences. The article concludes that the HSE Act is not adaptable to a farming environment and accordingly arguments are advanced for reform of the legislation.

\section{INTRODUCTION}

Farming in New Zealand is still considered by many as the backbone of the economy and the country. While this may be a matter of opinion it is indisputable that farming is one of the most dangerous industries in New Zealand. The Health and Safety in Employment Act (HSE Act) aims to reduce workplace accidents and so is applicable to farms as a way to reduce farm injuries. This article adopts a farmer perspective in order to determine what farmers' responsibilities are under the HSE Act. Farmers' compliance and reaction to the HSE Act will be examined by analysing results of a health and safety questionnaire completed by Taranaki farmers. The paper concludes with recommendations and conclusions regarding the HSE Act and its application to farms.

\section{FARM HEALTH AND SAFETY}

Farm health and safety is an issue of major importance. The average of 46 deaths per year occurring on farms between 1986 and $1991^{1}$ is evidence of the extent of the problem.

* This paper was submitted as part of the LLB(Hons) degree at Victoria University of Wellington.

1 J A Clarke, S W Marshall, J D Langley, C Cryer "Epidemiology of Injuries Occurring on New Zealand Farms" A Report to the Accident Rehabilitation and Compensation Insurance Corporation by the Injury Prevention Research Unit, University of Otago, March 1995, 54. 
This figure, can by way of example be contrasted to the average of nine deaths per year in forestry over the same period. ${ }^{2}$

A further selection of statistics highlights the problem.

(a) In 1990 people working in agriculture had an annual injury rate of 53 per 1000 which is above the national average of 41 per $1000 .^{3}$

(b) Of the average 46 deaths per year on farms an average of eight are children with the majority of these being boys. ${ }^{4}$

(c) Fifteen agriculture fatalities were investigated by OSH for the year ended 30 June 1996. This is to be compared to 12 in forestry, 20 in construction and 13 in factories and commercial premises. ${ }^{5}$

(d) A recent survey found that one in every two farmers suffers back pain, one in 5 had been injured by animals, and one in 10 had been injured while using farm machinery. 6

(e) Injuries on farms are also costly in financial terms. It is reported, for example, that for the 1990 financial year ACC claims from farm injuries totaled \$46.7million. ${ }^{7}$

The validity of some of these statistics can be challenged because it is difficult to know how many farm injuries are work related. Horse riding accidents, for instance, may have occurred during recreational or sports activities. A further problem is not knowing how many incidents involved visitors to the farm.

Nevertheless, the problems do not detract from the conclusion that farm injuries and deaths are at an undesirable level. Farm health and safety is a major issue and the

2 Above $\mathrm{n} 1$.

3 University of Otago Consulting Group "The Prevention of Injury Among Farmers, Farm Workers, and Their Families: A Programme for Development of Interventions for Rural Communities" Summary Report, February 1995, 1.

4 Above n 3, 32.

5 Occupational Safety and Health Service (OSH) Report to Provincial Chief Executives and Regional Policy Executives "Fatal Farm Accidents" 19 August 1996. Note that these are only those fatalities investigated by $\mathrm{OSH}$

6 As reported in 'The Farmers' and Growers' Guide to the Health and Safety in Employment Act 1992" (Occupational Safety and Health Service, Wellington, September 1993) 6-7.

7 Fact Sheet Number 8 "Injuries on Farms" (Injury Prevention Research Unit, University of Otago, Dunedin, 1996) 
question, therefore, is how does the Health and Safety in Employment Act address this problem and what impact has it had?

\section{THE HEALTH AND SAFETY IN EMPLOYMENT ACT}

The Health and Safety in Employment Act 1992 came into force on 1 April 1993. The HSE Act applies to nearly all places of work in New Zealand including farms. ${ }^{8}$ The implementation of the HSE Act constituted a consolidation of the law of health and safety in the workplace and coincided with a major rewriting of the accident compensation system. ${ }^{9}$

The principal object of the HSE Act is to provide for the prevention of harm to employees at work (section 5). The HSE Act is designed to achieve this object by promoting employer excellence in health and safety management.

The HSE Act focuses on employer-employee relationships and the short title explicitly refers to the Act as the Health and Safety in Employment Act. Therefore, farmers who are employers have the principal legal duties under this Act.

\section{A Occupational Safety and Health Service}

With the HSE Act came the creation of the Occupational Safety and Health Service, known as OSH, to operate as a division of the Department of Labour. OSH is responsible for the administration of the HSE Act and its primary role is health and safety education. It has the ability to issue improvement notices (section 39(5)) and prohibition notices (section 43) in regard to health and safety in the place of work. An improvement notice may specify what is needed to be done to comply with the law, while a prohibition notice suspends the particular operation until the legal requirements are met.

$\mathrm{OSH}$ also initiates prosecutions of any alleged offences against the HSE Act. OSH inspectors possess the sole right to prosecute alleged offenders of the HSE Act. Traditionally parties had to sue in common law if they wished to remedy a health and safety breach. Under the new provisions, parties who are not part of proceedings can receive a share of damages paid by the offender upon a successful prosecution by OSH. The key point is that OSH has access to the government purse to fund its case while the alleged offender does not.

8 The HSE Act does not apply to crew members on board an aircraft or ship. See s 2 (3) of the HSE Act.

9 It also followed major revisions of health and safety legislation in the United Kingdom and Australia. 


\section{B Key Terms Defined}

\section{Employer}

Section 2 defines an employer as any person "who or that employs any other person to do any work for hire or reward".

This means that farmers are employers if they take on staff and pay wages or other reward. Farmers are not employers if they have their family or friends assisting them. ${ }^{10}$ This is an important point because many farms make use of unpaid family members. Figures from 1990 show that 23 per cent of farm workers were unpaid family members and this figure had increased by 10 per cent between 1984 and 1990. In fact the majority of people (54 per cent) working on farms are farm owners and only 17 per cent were permanent paid workers and 6 per cent casual farm workers. ${ }^{11}$

\section{All practicable steps}

The HSE Act places no absolute duty on employers or others. Rather the duty is qualified by the requirement to take "all practicable steps". The standard is one of reasonableness. This is defined in section 2 :

All practicable steps in relation to achieving any result in any circumstances, means all steps to achieve the result that it is reasonably practicable to take in the circumstances, having regard to:

(a) The nature and severity of the harm that may be suffered if the result is not achieved; and

(b) The current state of knowledge about the likelihood that harm of that nature and severity will be suffered if the result is not achieved; and

(c) The current state of knowledge about harm of that nature; and

(d) The current state of knowledge about the means available to achieve the result, and about the likely efficacy of each; and

(e) The availability and cost of each of those means.

10 At common law there is a presumption that persons in a close familial relationship do not intend to create legally enforceable relations even when they undertake business and other financial transactions. See Fleming $v$ Beevers [1994] 1 NZLR 385, which follows the leading English case on this point Balfour v Balfour [1919] 2 KB 571.

11 Dr R M Houghton, A G Wilson, University of Otago Consulting Group "Injury to Farmers and Farm Workers, Community Networks Study: Working Paper 1: presented to Accident Rehabilitation and Compensation Insurance Corporation, June 1993, page 11. 
The "result" that the HSE Act talks about will always revolve around the protection of people from harm. For example, the prevention of people being harmed by an unguarded tractor power take-off (PTO) shaft. The HSE Act specifies that in deciding if "all practicable steps" have been taken to achieve this result, consideration must be given to each of the above factors (a) to (e). In the case of (a), death could result if the PTO is not guarded and someone becomes caught in it. Considering (b), the Accident Rehabilitation and Compensation Insurance Corporation (ACC) reports that most people who become caught in a tractor's PTO die. ${ }^{12}$ Under $(\mathrm{d})$, the remedial measure available is the fitting of a guard that will be effective in preventing anybody becoming caught. Considering (e), which may negate the need to take action, it is cost effective to fit a guard and the farmer will be expected to bear this cost. Therefore taking "all practicable steps" will require a guard to be fitted. ${ }^{13}$

The knowledge required under (b), (c) and (d) means that farmers must make reasonable efforts to keep up with new methods and new technologies. This may require an abandonment of doing things " the good old fashioned way". However, this will not always be the case as the standard of knowledge required is that of a reasonable farmer. Therefore, depending on the circumstances, a farmer is entitled to follow recognised and general practices that have been used for a substantial period of time without mishap.

Consideration must be given to the circumstances that existed at the time the duty of care was said to arise in determining if "all practicable steps" have been taken. ${ }^{14}$ Natural terrain is one such circumstance to be taken into account and will limit what is reasonably practicable in a farming environment. ${ }^{15}$ A farmer, therefore, cannot be held responsible for natural (and obvious) hazards on their farms, such as a river, though there may be a duty to fence them off.

\section{Duties of Employers}

\section{General duties under section 6}

Every employer shall take all practicable steps to ensure the safety of employees while at work. The HSE Act states that all practicable steps must be taken to:

(1) provide and maintain a safe working environment;

12 See Farm Equipment News, Issue 386, June 1997, 7.

13 A mechanical approach like this was adopted in Department of Labour v Wastecare Ltd, Unreported, 23 October 1996, District Court, Palmerston North, CRN 5054008810-11.

14 See Department of Labour v Lastel Construction Ltd [1995] DCR 121.

15 See Department of Labour v Ashby Hale Log Mover Ltd, Unreported, 29 September 1994, District Court, Henderson, CRN 4090003405. 
(2) ensure that plant used by employees is safe;

(3) ensure that working arrangements are not hazardous to employees;

(4) provide procedures to deal with emergencies that may arise in the workplace.

The emphasis is very much on the farm employer to deal with health and safety matters that involve their employees. The courts have been clear that employers must be pro-active, analytical and critical in providing and maintaining a safe working environment even to the extent of anticipating direct disobedience. ${ }^{16}$ The court in Mair $v$ Regina ${ }^{17}$ noted that employers may have to anticipate irrational, unwitting, or unthinking behaviour by their employees. Court rulings such as this erode individual responsibility and place heavy burdens on the employer. ${ }^{18}$

The common law has long placed a duty on employers not to expose employees to unnecessary risk of injury. ${ }^{19}$ The provision of safe and proper plant and equipment is regarded by the court as a paramount duty upon the employer. The standard required is to take "all reasonable care". Therefore, the HSE Act imposes a different requirement, being a duty to take "all practicable steps".

\section{Hazard management}

The thrust of the HSE Act is hazard management with s 7 requiring every employer to ensure that there are in place effective methods for-

(a) systematically identifying existing hazards to employees at work; and

(b) systematically identifying new hazards to employees at work: and

(c) regularly assessing each hazard identified, and determining whether or not it is a significant hazard.

16 See Mair v Frasers Bacon Ltd, Unreported, District Court, 24 February 1994 CRN 3012009612. This is not to say that farmers are expected to bear the liability for all employee mistakes and accidents, it depends entirely on the individual circumstances. In one case an employer was not liable under s 6 when a linesman ineptly felled a poplar tree which he had been specifically instructed not to fell. See Department of Labour v Powermark [1996] DCR 224.

17 Unreported, 4 March 1994, District Court, Dunedin, CRN 3045004405.

18 Section 19 of the HSE Act places responsibility on employees not to harm themselves or any other person while at work. This section mitigates the apparent overwhelming burden of the employer to be responsible for the prevention of harm to employees. However, regardless of s 19, the law is clear that the onus for health and safety falls squarely on the employer's shoulders.

19 See Wilsons and Clyde Coal Co v English [1937] 3 All ER 628. 
This means farm employers have a responsibility to identify, assess and control hazards.

(a) Identify hazards

A hazard is any activity, circumstance, process, situation, or substance that is an actual or potential cause or source of harm. ${ }^{20}$

The broad scope of hazards effectively means that everything on a farm is a hazard. Table One highlights the abundance of hazards on farms by applying farm examples to every one of OSH's eleven categories of hazards. ${ }^{21}$

Table One

Hazard

1 Chemical

2 Noise

3 Radiation

$4 \quad$ Electrical

$5 \quad$ Lighting

6 Vibration

$7 \quad$ Temperature

8 Biological

9 Ergonomic

10 Physical

11 Miscellaneous
Farm Example

Herbicides, pesticides and veterinary medicines

Chainsaws, tractors, grinders, pig house at feeding time

Sunlight, welding

Underground cables, overhead wires, electrical equipment

Working before sunrise and after sunset

Sitting on a tractor or using a chainsaw

Working in extremely hot or extremely cold conditions

Brucellosis, leptospirosis, bacteria

Manual lifting, shearing, milking

Machinery, natural and man made obstacles

Stress, fatigue

Table One shows that all types of hazards exist on the farm plus more that are not categorised such as water hazards (oxidation ponds and troughs) and equipment such as firearms.

The key term "effective" is not defined by the HSE Act. The Oxford dictionary defines it as meaning "having a definite or desired effect as well as actual". Rewording farmers' obligations under section 7 requires the employer to have in place actual

20 Harm means illness, injury, or both.

21 Categories obtained from How to Identify and Control Hazards in the Workplace, (OSH, January 1994). 
methods of hazard identification and assessment. Therefore, a positive duty is on the farmer to find hazards, preferably before they arise. Certainly a farmer will be expected to have knowledge of existing hazards.

While Table One illustrates some hazards, the main ones on a typical farm will be tractors, motorbikes, chainsaws, chemicals, stock handling, electricity, noise, machinery, water and exposure to the sun. Complying with the identification requirement may require much work due to the nature of a farm and the number of hazards present. Nevertheless, this is what the law requires.

The key term "systematic" is not defined in the HSE Act either. It can be interpreted as a requirement to have some procedure behind the methods of hazard identification. So while there is no obligation to have the methods and results in writing, lack of them will put in doubt the system's effectiveness.

(b) Assess hazards

Identified hazards must be assessed to determine if they are significant. ${ }^{22} \mathrm{~A}$ risk assessment is required to determine if a hazard is a significant one. The farmer should ask himself or herself the following key questions:

(1) How could any illness, injury or damage result from this hazard?

(2) What is the degree of harm Is it fatal, major, minor or negligible?

(3) How likely is it that the harm will occur, eg happens all the time, strong possibility, remotely possible?

If the hazard is an actual or potential source of serious harm then it is a significant hazard. With the information from the three questions above, hazards can be prioritised. Those hazards that are a source of the highest harm, and are likely to occur the most frequently, should be dealt with first. Significant hazards must be controlled in a specific manner in accordance with sections 8, 9 and 10 of the HSE Act which are discussed below.

Judge Keane in Department of Labour v McVicar Timber Group L $t d^{23}$ said that it does not matter whether the risks are rated high or low. If they exist, employees must be

22 "Significant hazard" means a hazard that is an actual or potential cause or source of -

(a) serious harm (such as death, poisoning, burns and amputation of a body part); or

(b) harm whose effects depend on a persons' extent or frequency of exposure to the hazard; or

(c) harm that occurs, or in not easily detectable, until sometime after the initial exposure.

Examples of (b) and (c) include exposure to chemicals, noise, fumes and dusty materials.

Unreported, District Court, 6 October 1993, Blenheim, CRN 3006005655, CRN 3006005657. 
protected. The identification of dangerous hazards should be the starting point for controlling hazards.

While not mandatory, documentation is definitely advisable to any farmer as proof that such a system exists. Furthermore, the complexity of farming will mean that documentation is the easiest way to manage the hazards. ${ }^{24}$

(c) Control hazards

The key responsibility on farm employers is hazard elimination, isolation and minimisation.

If practicable, significant hazards must be eliminated (section 8). It is obvious that farmers cannot eliminate hazards such as tractors and chainsaws but the law does not require this as it would not be practical. Hazards such as unused chemicals should be disposed of and unsuitable equipment should be replaced.

If it is impracticable to eliminate the hazard then it must be isolated it (section 9). A farmer must therefore put some distance between the hazard and the employee (section 10). The use of guards on plant and using an isolating transformer with electrical tools outdoors are examples of isolating hazards.

Where elimination or isolation is impractical or ineffective then the farmer must take all practicable steps to minimise the likelihood that harm from the hazard will occur. This is achieved by the provision of and use of suitable safety equipment and clothing such as supplying earmuffs for chainsaw use and ensuring that the saw is well maintained. Adequate training of employees, the use of sunscreen and the following of safe and accepted work practices are further ways to minimise the risk of harm.

Furthermore section 14 states that employees must be involved in the development of the hazard management plan. If these steps are fully followed the farmer would have taken all practicable steps to achieving the prevention of harm to employees.

A hazard management duty has long existed at common law. The classic case is Goldman $v$ Hargrave ${ }^{25}$ where a farm tree struck by lightning was felled and left to burn out. Unfortunately winds picked up, reviving the fire and caused it to spread and damage neighbours' property. The farmer was held liable for failing to act with reasonable prudence so as to remove the hazard (the fire). The court clearly stated that a positive duty to deal with hazards depends upon (1) knowledge of the hazard (2) ability

24 This is to say that the range of activities undertaken, the hours worked, and the conditions endured on a farm mean that the industry is more complex than any other.

25 [1966] 2 All ER 989. 
to foresee the consequences of not checking or removing it and (3) the ability to abate it. The standard is what it is reasonable to expect in the circumstances. Therefore, the HSE Act is different from the common law duty because it focuses on a duty to actively identify hazards in addition to controlling them.

\section{Duty to inform and train employees}

Employees must be given information of all identified hazards and the hazards that they may create while at work. Information about where all safety clothing and equipment is kept and information on what to do if an emergency arises on the farm must also be disseminated.

Employers have a duty under section 13 to ensure that employees have knowledge and experience of the activity that they are to engage in. Otherwise the employer must ensure that the employee is supervised.

Under section 13 the employer must take practicable steps to ensure their employees are adequately trained in the safe use of all plant, machinery and equipment that they may be required to use. Court cases to date have decided that "adequate" does not involve a high level of training. ${ }^{26}$ Farmers must simply teach their employees the safe methods of carrying out activities. Common sense dictates that the higher the risk of harm in the activity, the more the effort that should go into training. Retraining from time to time may also be required to satisfy the adequate training test. ${ }^{27}$

Even if employees are hired on a casual basis section 13 applies and employees may have to be trained. ${ }^{28}$ The court in Independent Fisheries ${ }^{29}$ even went to the extent of saying that the importance of training casual staff cannot be over-emphasised because this group of workers are often not as mindful of their own safety as they should be. ${ }^{30}$ Those farmers who are not full-time employers must be aware that section 13 duties exist whenever they hire part-time employees.

26 See Department of Labour v Talleys Fisheries, Unreported, District Court, Blenheim, February, 1994, CRN 3006005658/60.

27 SeeDepartment of Labour v Southpower, Unreported, District Court, Christchurch, 1 September 1992, CRN 1009028463.

28 See Department of Labour v Independent Fisheries, Unreported, District Court, 13 June 1994, CRN 3009027671.

29 Above $\mathrm{n} 28$

30 Above $\mathrm{n} 28$. 


\section{Accident register}

Section 25 requires farm employers to maintain a register of accidents and serious harm that occurred on the farm. Every accident that is duly recorded must be investigated to determine if the accident was caused by, or arose from, a significant hazard (section $7(2)$ ). Serious harm must be reported to OSH by the employer within seven days (section 25(3)). OSH may then decide to investigate the accident. If it does so, the accident scene must not be interfered with. ${ }^{31}$ It is also mandatory to record near-miss accidents.

\section{$D$ Duties of the Self-employed}

Self-employed farmers, those who do not employ any staff, have a positive duty under section 17 to protect themselves and others. The focus is much the same as in sections 6 and 16 farmers must take all practicable steps to ensure that no action or inaction by them harms them or any other person on the farm. Unlike employers, there is no legal requirement to have a hazard management plan. However, such a plan would be evidence that "all practicable steps" have been taken to prevent hazards causing harm.

\section{E Duties on Principals}

A "principal" is defined in section 2 as "a person who or that engages any person (otherwise than as an employee) to do any work for gain or reward". Farmers are principals, for example, when use is made of shearers, relief milkers, or fencers.

Principals must take all practicable steps to ensure that contractors are not harmed while doing any work that they are engaged to do. This means that some connection between the practical steps a farmer can take and the actual prevention of harm to the contractors must exist. The farmer, for example, cannot be held accountable if contractors are injured while using the tools of their trade. Farmers are only responsible for activities that they can control. Contractors will have to be warned of such things as unsafe tracks or overhead powerlines, where appropriate, to satisfy the "practicable steps" duty.

\section{F Duties of All Farmers}

\section{Section 16}

Section $16^{32}$ means that all farmers have a responsibility to members of the public who come onto their property for whatever reason. Farmers must take "all practicable

31 However, s 26 allows valid excuses for accident scene interference. These include where it is vital to save or help someone, or prevent serious damage to property, or to enable vital public access ( $\mathrm{s}$ 26).

32 Section 16. Duties of persons with control of places of work- 
steps" to ensure these people are not harmed by any hazard that is in or arises in the "place of work" (the farm). ${ }^{33}$ For example they should warn trampers of dangerous animals and ensure people are adequately trained before using any farm vehicles or equipment.

Section 16 has been, and continues to be, the subject of much debate amongst farmers. The two major cases on this point, Berryman ${ }^{34}$ and Perriam ${ }^{35}$, result in uncertainty with regards to farmers' responsibilities.

\section{The Berryman case}

Berryman farmed a property in the King Country owned by his wife. For all practical purposes the only access to the property was by a suspension bridge over the Retaruke River. The bridge led from a public road to the farm and Berryman accepted responsibility for it. Richards was a self-employed beekeeper who operated hives on the farm. In March 1994 Richards was killed when the honey-laden ute he was driving crashed through the decking of the bridge and fell into the river below. The evidence showed that the timber bearers which supported the decking were in a poor condition due to weathering and rotting. Berryman was unaware of the state of the bridge.

OSH initiated a prosecution to charge Berryman under section 16 for failing to ensure Richard's safety in his "place of work" as defined in section 2(1). It is important to note the extended definition of a "place of work" only applies to employees. ${ }^{36}$ If Richards was

To the extent that a person is-

(a) The owner, lessee, sublessee, occupier, or person in possession of a place of work or any part of a place of work (not being a home occupied by the person); or

(b) The owner, lessee, sublessee, or bailee, of any plant in a place of work (not being a home occupied by the person),-

the person shall take all practicable steps to ensure that people in the place of work, and people in the vicinity of the place of work, are not harmed by any hazard that is or arises in the place of work.

33 Under s15 employers also have a specific duty to ensure that no action or inaction of employees while at work harms any other person. See Health and Safety Inspector $v$ Glenhouse Service Station, Unreported, District Court, Dunedin, 12 August 1994, CRN 4012004953-44 where a farmer was seriously injured when the tractor tyre he was inflating at the garage exploded. The garage owner was found liable under s15 for failing to instruct staff to prohibit members of the public from inflating such tyres.

34 Department of Labour v Berryman [1996] DCR 121.

35 Health and Safety Inspector v Perriam, Unreported, District Court, Alexandra, 25 May 1994, CRN 3002004421-22.

36 "place of work" means a place (whether or not within or forming part of a building or structure) 
working in a "place of work" of which Berryman was the "occupier", then Berryman was under a duty to take all practicable steps to ensure that Richards was not harmed by any hazard in that "place of work." The Court had no difficulty in finding that Berryman was the occupier of the bridge and the issue was to examine "place of work" and decide if the bridge could be classified as such.

The prosecution argued that the bridge was a "place of work" for Berryman since he was responsible for its maintenance. The Court rejected this argument saying that "place of work" in section 2 denotes some degree of frequency rather than mere intermittent activity over a number of years. The Court expressed concern that if the bridge was Berrymans place of work then: ${ }^{37}$

\footnotetext{
...an uninvited travelling salesman, a neighbour...and a relative coming to stay...for Christmas would all be entitled to the protection of the Health and Safety in Employment Act in respect of the state of the bridge. In view of both the short and long title of the HSE Act, that would seem an unlikely outcome.
}

The long title of the HSE Act states that the HSE Act is to reform the law relating to health and safety of employees, and other people at work or affected by the work of other people. The long title does acknowledge scope for duties to be owed to non-employees. Nevertheless the Judge continued by saying that: ${ }^{38}$

such an outcome would mean that Parliament has created general criminal liability for dangerous buildings or structures by means of an enactment which is essentially an employment related statute. In all circumstances, and taking particular account of the objects of the HSE Act as expressed in section 5, that is not an inference which I am prepared to draw.

The prosecution argued in the alternative that the bridge was a "place of work" for Richards because he was "working" when he drove over it. Defence counsel submitted that the bridge was merely Richard's access to his "place of work". The court decided that "place of work" is intended to connote a place where a person is working in more than a

where any person is to work, is working, for the time being works, or customarily works, for gain or reward; and, in relation to an employee, includes a place, or part of a place under control of the employer (not being domestic accommodation provided for the employee),-

(a) Where the employee comes or may come to eat, rest, or get first-aid or pay, or

(b) Where the employee comes or may come as part of the employee's duties to report in or out, get instructions, or deliver goods or vehicles; or

(c) Through which the employee may or must pass to reach a place of work.

37 Above n34, 132. 
transitory sense. ${ }^{39}$ There is no doubt that if Richards had been an employee of Berryman, then the bridge would have been a "place of work" and Berryman would have been found liable under section 6 . This ruling means that employees are still covered because of the extended definition of "place of work". If a farm employee leaves his or her "place of work" they will have the HSE Act's protection as long as it is for an employment related purpose and the place in question is still under the control of the farmer.

Several comments may be made in light of Berryman: ${ }^{40}$

(1) "Place of work" involves a degree of frequency in the activity and involves something more than working in a transitory sense. Therefore farm tracks and access ways will generally not be "places of work" for visitors.

(2) The "grey area" of the law with regards to non-employees in a "place of work" is highlighted and this "grey area" creates uncertainty with regards to a farmer's duties.

(3) The HSE Act is not intended to be a statute which creates a range of general criminal offences which have only a tenuous link to a work environment. ${ }^{41}$

(4) Parliament did intend some protection for non-employees. Therefore loopholes exist in the law and Berryman was not convicted due to a technicality. This creates uncertainty and disrespect for the law.

(5) Doubt is cast on whether mobile employees, for example police officers and meter readers, are covered by section $16 .^{42}$

\section{The Perriam case}

In this case a farmer was successfully prosecuted under section 16 for failing to take all practicable steps to ensure a child's safety in a woolshed. A three year old daughter of one of the shearers injured her arm when she put it in the machine on the wool conveyer table in Perriam's woolshed. Perriam had previously asked for the child to be removed and had put a cardboard guard on the machine when the child was not removed. The court held that by putting up a makeshift guard Perriam had recognised that a hazard existed and should have either removed the child or shut the machine down. Since the

39 The Berryman case was dismissed as the bridge was not found to be a "place of work".

40 Above $\mathrm{n} 34$

41 Above $\mathrm{n} 34,135$.

42 See ELB Issue no 7, October 1996, 119. 
latter was not practicable in the circumstances the child should have been removed to satisfy the " all practicable steps" duty.

Several comments may be made in light of Perriam: ${ }^{43}$

(1) If a farmer cannot protect people in a "place of work" then they should not be present. This justifies some farmers refusing or restricting access to their farm to avoid potential liability.

(2) "All practicable steps" is a vague term. The farmer clearly thought he had done enough in the circumstances, given that he was probably too busy to be concerned with the child, had asked for the child to be removed and had erected a make-shift guard.

(3) Doubt remains about the extent of farmers' responsibilities under the HSE Act.

(4) Valid reasons for changes to be made to the law exist.

\section{THE HSE AMENDMENT BILL 199644}

\section{A Background}

Concern arose soon after the enactment of the HSE Act about its implications for farmers, especially farmers' obligations towards visitors. This concern was exemplified by the Berryman and Perriam cases. Federated Farmers met with OSH and the Fish and Game Council ${ }^{45}$ to discuss these implications in 1994. The Recreational Users Group ${ }^{46}$ was formed in 1995 to address the problem and propose a solution.

\section{B The Problem}

The interpretation of section 16 of the HSE Act in Berryman and Perriam has left in some doubt the responsibility of farmers to people who are on the farm for non-workrelated purposes, typically recreation, either with, or without, the farmer's permission. As a direct consequence of section 16 "some farmers have barred scout groups, hunting clubs, shooters, meter readers and Telecom technicians from their properties rather than risk the hefty fines should an accident occur". ${ }^{47}$ Farmers are not allowing public access to

43 Above $\mathrm{n} 35$.

44 As at 10 February 1998 the Bill is awaiting reading before the Committee of the Whole of the House (Parliament). [Ed This Bill became the HSE Amendment Act 1998 on 18 March 1998.]

45 The Council was concerned about anglers and hunters being denied access to or across farms.

46 The group consisted of representatives from OSH, Federated Farmers, The Fish and Game Council, Sports Assembly, Federated Mountain Clubs and The Adventure Tourism Council.

47 See "Changes to law may solve farm dilemma" Sunday Star Times, Auckland, New Zealand, A5, 
their farms even if the potential problem or liability is very small. ${ }^{48}$ At the same time many recreational users accept responsibility for themselves when they pursue their outdoor activities. ${ }^{49}$ Furthermore, while the legislation is being used as an excuse to stop public access, it is also being used as a way of imposing charges for access, including the sale of sole access rights to commercial operators such as fishing guides. ${ }^{50}$

\section{The Solution ${ }^{51}$}

The Health and Safety in Employment Amendment Bill 1996 limits section 16 so the duty is owed only to those people who are in a "place of work" for some purpose connected with the work activities. Therefore, if enacted, it will effectively remove the potential liability of farmers in relation to those who are on the land for reasons not relating to the work being carried on there. ${ }^{52}$

This will overcome the recreational use problem. Farmers will have no responsibilities, for example, to bike riders, trampers or duck shooters. Furthermore, removing duties to non-employees is in line with the principal object of the HSE Act and those views expressed by the court in Berryman.

V TARANAKI FARMERS' LEVEL OF COMPLIANCE AND REACTION TO THE HSE ACT

\section{A Introduction}

One hundred Taranaki farmers were mailed a questionnaire containing 18 questions regarding health and safety on farms and in particular on the HSE Act. ${ }^{53}$ The purpose of

June 11997.

48 Health and Safety in Employment Amendment Bill, Submission of The New Zealand Fish and Game Council to the Social Services Select Committee, 4 April 1997.

49 Above $\mathrm{n} 48$.

50 Above $\mathrm{n} 48$.

51 The Social Services Committee which examined the Bill proposed that $\mathrm{s} 16$ be repealed altogether and a new s 16 substituted. Under the proposed new s 16 no duty would be owed to people present for the purpose of recreation or leisure, except if they had consent to be there and either paid to be there or were to buy or inspect goods.

52 A concern with the Bill is that it applies to all 'places of work' and is not just specific to farmers and open rural land as was the original intention.

53 Taranaki was chosen because this is the author's home province and therefore special interest existed in testing this area. A copy of the questionnaire is contained in Appendix One of the original versions of the paper held in the Victoria University of Wellington Law library. The questionnaire was written by the author with some guidance from Federated Farmers whose assistance is acknowledged and valued. One hundred farmers' names and addresses were 
the questionnaire was to test Taranaki farmers' level of compliance with the HSE Act and to interpret the results. Given farmers' duties under the HSE Act the questions focused on testing the impact of the legislation in creating a safer farm environment.

\section{B Results}

\section{Employers}

The majority of farmers surveyed were employers which means they have the principal responsibilities under the HSE Act. One farmer responded that taking responsibility for unpredictable behaviour of employees is a real disincentive to employ anyone. Non-employer farmers still have responsibilities as self-employed (section 17), as principals (section 18) and persons in control of a place of work (section 16), though, as the cases demonstrate, some doubt surrounds the latter.

\section{Knowledge of the HSE Act}

The level of awareness among farmers of their responsibilities under the HSE Act was tested. The majority of farmers were either definitely or sort of aware of their responsibilities. As was expected, farm employers had a higher level of awareness of their duties than non-employers. Yes definitely was answered by 42 per cent and 19 per cent respectively. Considering there exists uncertainty as to farmers' duties in relation to non-employees on the farm, the 19 per cent result is not surprising for non-employers. One farmer stated that "I am aware that I'm a sitting duck". ${ }^{54}$ However, considering that the majority of farmers knew of only some of their responsibilities under the HSE Act (53 per cent of employers and 65 per cent of non-employers), the result indicates room for improvement. This places the emphasis on the farmer to get informed and OSH to educate. No farmer claimed to know nothing about the duties.

Just over half of the farmers, 53 per cent, had attended at least one meeting run by $\mathrm{OSH}$ to explain the HSE Act. The feedback was mostly critical of OSH whose speakers were considered pompous, patronising and with no idea of the realities of farming. Presentations were described as unprofessional and unrealistic. Farmers generally felt

randomly chosen from a database of over 400 Taranaki farmers compiled largely by Brian Stallard. His assistance is greatly appreciated. Questionnaire participants were mailed the survey along with a self-addressed envelope containing the author's address. Many thanks to Victoria University of Wellington for providing the funding. Seventy six questionnaires were returned and results were collated by the author using Microsoft Excel. Statistics can also be viewed in the unedited version of this paper.

54 A farmer who complies with the HSE Act's requirements will not be a sitting duck. However, what the farmer is alluding to is either not knowing how to comply, or whether there has legally been compliance. This is due to uncertainty over duties to visitors and the difficulty in not knowing if all practical steps have been taken in a farming context. 
that the OSH philosophy of trying to make life super-safe was mis-directed. Clearly OSH has damaged their reputation and lost respect with their often uncompromising, unprofessional, and inexperienced approach. It also seems that farmers are uneasy with the fact that $\mathrm{OSH}$ has the dual role of educator and prosecutor. While one farmer reported attending an excellent presentation, in general the relationship that exists between OSH and Taranaki farmers is not optimal and improvements in this area are desirable. Perhaps the solution is the education of farmers by farmers, and having this pitched at a level that enable farmers practically to make changes. ${ }^{55}$

Nearly all, 99 per cent, of farmers support the HSE Act's objective of preventing harm to people in the workplace. However, many farmers felt the need to qualify their answer. Farmers commented that legislation was not, and is not, going to change a basic human instinct to protect people. It was also considered necessary that more common sense apply and for employees to take responsibility for themselves. Other farmers saw the HSE Act as a mechanism to lower ACC costs.

\section{The HSE Act's Impact}

The questionnaire was designed to gain insight into farmers' health and safety focus on the farm. Approximately half the farmers stated that they were always conscious of health and safety. Of these 51 per cent and 45 per cent were employers and nonemployers respectively. These figures appear shockingly low but when almost always is added the figure rises to 83 per cent for all farmers ( 84 per cent of employers and 80 per cent of non-employers). Some farmers admitted that when it comes to health and safety it is hard to think of everything, but this can be put down to the nature of farming. One farmer commented that dairy farming is labour intensive, naturally causing overextension to occur and making it difficult to be on top of everything all the time. It is pleasing to note that no farmer was hardly ever or never conscious of health and safety. Therefore given the nature of farming the figures are reasonably high, but obviously improvements are always desirable. The results do prove that farmers are concerned about health and safety on their farms.

The impact of the HSE Act and establishment of OSH upon farmers' attitudes and practices regarding health and safety was tested. The questionnaire specifically asked farmers if the HSE Act and OSH had changed their approach to farm safety. Thirty-six per cent of farmers said yes definitely, while yes sort of and no not really both scored 29 per cent. The divergence in results between employers and non-employers is significant. 42 per cent of employers answered yes definitely compared to only 26 per cent of nonemployers. In fact 55 per cent of non-employers said that the operation of the HSE Act

55 The point is that health and safety "words" are meaningless and what is desired is "action". 
and OSH had not really or not at all changed anything compared to only 20 per cent of employers. It must be borne in mind that those who answered not at all included farmers who have always regarded safety as a number one priority. However, the conclusion is that the HSE Act and OSH have had a big effect on employers but not so much on nonemployers. Since the HSE Act primarily focuses on employers to take responsibility for health and safety, it could be expected that employers will have changed attitudes and practices to comform with the legislation.

While prima facie the above figures indicate the HSE Act is successful, this is a misleading conclusion because of the nature of some comments expressed. Positive effects such as being more aware of health and safety responsibilities and the provision of safety gear were indicated, but the negative effects may outweigh these benefits. One such effect is the restriction and refusal to allow recreational visitors on the farm. Other negative effects included employees missing out on doing certain tasks on the farm, such as operating chainsaws, while another never allows anyone to do anything without the farmer's supervision. Therefore the HSE Act has had an impact but not always for the better.

Given the results above, the questionnaire asked how important was potential prosecution in influencing farm health and safety. Has the "stick", ie, threat of prosecution, been the factor which changed approaches and perceptions, or was it the better prevention of harm to people. Of all farmers 26 per cent stated yes definitely the "stick", made up of 31 per cent employers and 19 per cent non-employers. The employers' figures are significantly higher and understandable. Since employers have the most duties they also have a greater chance of breaching those duties and being prosecuted. One farm employer said prosecution had raised the stakes and employees were moving from a position of advantage to liability in employers' eyes. The comments of those who said that prosecution had not really or not at all had effects ( 28 per cent and 58 per cent of employers and non-employers respectively) centred on not wanting an accident on their farm, whether prosecution existed or not. To quote one self-employed farmer; "I am running a farm on my own like a big majority of farmers and cannot afford to be off work sick or from accident". In summary, the statistics show that for employers the "stick" is bigger than the "carrot", while for non-employers the reverse is evident.

The questionnaire revealed the negative effects of the HSE Act. Twenty-one per cent of farmers have restricted or refused access to their farm because of the HSE Act. Farmers comments to justify their action is eloquently summed up by one farmer who said "No access - No risk". The 21 per cent figure is high and it does not take account of those farmers who have yet to have occasion to test their reaction. The extreme measure taken by farmers to "lock their gates" to the public is an undesirable consequence of the HSE Act. It is a result of the inability to define "all practicable steps" for a farming 
situation and uncertainty over section 16. It is a real concern for all parties involved, whether it be farmers, recreation users or OSH. The ability to remedy this problem with the Amendment Bill would be a welcome relief for farmers. It is not surprising then that 95 per cent of farmers support the Health and Safety in Employment Bill 1996. The underlying theme in most views was the need to place the bulk of responsibility on the individual. One farmer put it best by saying that the old adage of "pack your own parachute" is appropriate. Farmers also felt that common sense is the best defence on a farm.

\section{Hazard identification}

The HSE Act requires employers to have a hazard management plan and to have identified hazards on the farm. The questionnaire revelaed that only 11 per cent of employers have set up such a plan and (while not mandatory) less than half of these farmers have the plan documented. Twenty-five per cent of employers stated that they have identified some of the hazards but a majority (64 per cent) had not done anything. The simple conclusion is the majority of employers are not complying with the law. This is an interesting result because while the majority of farmers indicated that their attitudes had changed, this has not corresponded to change in activity. The crucial question is, why are the figures so low considering the majority of farmers' support the HSE Act's intention and regard health and safety as an important issue?

Question 11 was purposely added on the assumption that farmers would not have taken the required steps to identify hazards and thereby attempt to answer the above question. The most common reason for employers not having identified hazards on the farm was the impracticality of doing so. Farming by definition involves many hazards. Many activities on a farm involve a combination of natural hazards and man-made hazards making it difficult to isolate and assess each. The next two reasons rated equally and were dealing with hazards effectively as they arose and not needing a plan because farm safety is common sense. Table Two lists the reasons and rankings as follows: (The percentage is the portion of employers who included the reason as one of their own.)

Table Two

$\begin{array}{llc}\text { Rank } & \text { Reason } & \text { Percentage } \\ 1 & \text { Find it's too impractical. Too many hazards exist on the farm. } & 58 \\ 2= & \text { Deal with hazards effectively as they arise. } & 38 \\ 2= & \text { Don't need a plan, it's common sense. } & 38 \\ 4 & \text { Don't have the time. } & 22 \\ 5 & \text { Don't know what the law requires. } & 18\end{array}$


Some comments give further insight. Farmers asked why, if the HSE Act requirements are easy to comply with, does OSH not have a complete and total hazard publication? The obvious answer, as many farmers pointed out, is that everything on the farm is a hazard. Others stated that the size of their farms made the task daunting and impractical. One farmer pointed out that hazards are not avoided by writing a list of them and hanging them on the shed wall. Rather accidents are avoided by using common sense.

It is obvious that farmers are not complying with this part of the law, not because they do not know what the law requires (only 18 per cent), but because the law does not cater for a farming environment that farmers can practically adhere to. Herein lies the conflict between the HSE Act and the farming environment. The HSE Act requires all practicable steps to be taken to identify and eliminate or reduce hazards but farmers do not find this requirement practical. This raises the unanswered question whether they have in fact, or at least in law, satisfied the "all practicable steps" test?

\section{Safety gear}

Compliance with sections 10 and 15 of the HSE Act was tested in the questionnaire by reference to the provision and use of safety gear when dealing with chemicals. Twentysix per cent of farmers provide safety gear for their employees or use the gear themselves all of the time while 25 per cent said they do almost always. Sometimes providing and using the gear involves 22 per cent of farmers, hardly ever 11 per cent and never 9 per cent. In terms of the HSE Act and what is practicable anything less than always or almost always would probably be deemed unacceptable. This category involves just over half (52 per cent) of farmers not complying with the HSE Act's provision of minimising hazards, the hazard being the chemicals. Remarks included admitting that protective gear should be used more often and finding it impossible to police whether employees are actually using the gear that has been provided. One farmer declared, "I have been told to get rid of staff if they don't use the safety gear... I think the powers to be [OSH] do not know how difficult it is to get staff on back country property!" While chemical safety is an area that farmers need to address, responsibility should rest upon the individual to use the gear provided. Requiring farmers to supervise or constantly check upon their employees is not always practicable and may in fact defeat the purpose of employing staff to enable the farmer to do jobs elsewhere. 


\section{Section 16}

With regards to section 16, "all practicable steps" may be satisfied by warning visitors to the farm of hazards to avoid or look out for. Question 13 asked if farmers adopted this practice and 26 per cent of all farmers said yes always, 24 per cent almost always and 26 per cent sometimes. Given that warnings will not always be necessary, as one farmer said "I would only warn if I thought they [visitors] may be in danger", the figures are reasonably high. Hardly ever and never rated only 13 per cent and 5 per cent respectively. Farmers warn people on the farm because it is commonsense to do so. Therefore despite this aspect being relatively well complied with, the important question is are warnings sufficient to satisfy the "all practicable steps" requirement? Given the consequence of farmers refusing public access to their farms and the uncertainty of duties due to the Berryman and Perriam cases the answer is probably no. If the answer is no then the Amendment Bill is certainly justified.

\section{Accident register}

Farmers were asked if they maintained a register of accidents in. An overwhelming 78 per cent of employers said never. Only 16 per cent and 4 per cent said "yes always" and sometimes respectively, which indicates that the level of compliance among farm employers is extremely low. Non-employers, who do not have this duty, scored approximately the same as employers. However, the figures may be misleading as this question provoked the most comment with many farmers saying that they have not had any accidents yet to record and hence ticked the never box. While the figures may be over inflated, it is fair to conclude that the level of non-compliance is high. The requirement to record accidents that "might have harmed" was met with a hostile reaction from some farmers. Farmers regard it as a ridiculous and impractical requirement because even stepping on a farm is a risk. To quote one farmer: "I am more interested in avoiding accidents than wasting time and paper recording them". In summary, farmers have difficulties with the practicality of the obligation to record near-miss accidents.

\section{Vehicle Safety}

The questionnaire tested farmers' compliance with the HSE Act this time by reference to vehicle safety and primarily relevant under section 13 for employers. The results showed 78 per cent of employers ensure that their employees and others are adequately trained and have sufficient knowledge and experience to be able to operate vehicles such as tractors and motorbikes. The figure is even higher for non-employers at 87 per cent who may have duties under section 16 to others operating vehicles on the farm. One farmer commented that it inevitably costs the farmer if vehicles, and other gear for that matter, get wrecked. Other comments highlighted training as not being a sufficient condition to ensure safety with other factors, such as experience and well maintained 
equipment, playing important roles. If accidents occur on the farm it is the farmer who must bear the costs, whether it be hiring extra staff or replacing damaged equipment. It makes sense, therefore, to ensure vehicles are operated safely regardless of the HSE Act.

\section{Practicality versus commonsense}

The questionnaire asked if farmers climbed or clambered up the front of the square bales haystack, whether in a shed or not, to reach the top. The safest method is to use a ladder or some other means and not to pull oneself up the stack. Intuition and first hand knowledge suggested that farmers did the latter and so the question was a direct way to provide evidence. Half the farmers, to whom the question was applicable, stated yes and 24 per cent said sometimes giving a combined total of 75 per cent, which is the great majority of farmers. Those farmers who answered no used methods such a ladder, rope, backing the tractor in and using the tractor front end loader. Since the results appear to fly in the face of the farmers' argument that farm safety is common sense, can the figures be explained and justified? The answer is yes because the issue is one of practicality. As one "guilty" farmer validly pointed out employees also have to climb up the side of a steep hill when mustering, without a ladder!

To most people common sense would tell them that a ladder should be used. This illustrates the differences between farmers' perceptions and other peoples' perceptions. To a farmer the issue is one of practicality. It is neither practical to store a ladder in the hayshed nor to cart one there when needed. Common sense for a farmer dictates that when climbing up a haystack (typically close to the shed wall anyway), take care and be cautious. Experience is the key. This specific example demonstrates that farm practicality and others' perceptions of commonsense (or lack or it) do not necessarily equate.

\section{Questionnaire Conclusion}

Eight keys points emerge from the survey results and comments.

(1) The response of 76 per cent of the questionnaires returned indicates that farmers are concerned about the HSE Act's application to farm health and safety.

(2) Farmers regard health and safety as an important issue and do not want to see people hurt on their farms.

(3) It is in the farmers' best interests to operate the farm safely as they invariably bear the costs of accidents.

(4) While indications are that Taranaki farmers are changing their attitudes towards heath and safety this has not resulted in actual changes. The level of compliance with the HSE Act is not particularly high. 
(5) For farmers the bottom line is that the HSE Act's requirements are not always practical for a farming situation.

(6) Farmers have not been impressed by the approach OSH has taken to the education and prosecution of health and safety issues.

(7) With farm safety the bulk of responsibility must lie with the individual to take care of themselves.

(8) The questionnaire results raise good arguments for change. Farmers support the Health and Safety Amendment Bill and would undoubtedly support further changes emphasising common (and safe) practices and individual responsibility. However, it must be proven that farming is different from other industries to justify any specific change to the status quo for farmers.

\section{ARE FARMS DIFFERENT FROM OTHER INDUSTRIES? 56}

Farming is a unique environment and the following list indicates why this is so.

(a) The farm is also the place of residence and recreation for the farmer, farm workers and their families. This is the main point, because essentially there are two populations on a farm. The working population and the residing population (typically children). Often a farmer will combine farm work with parenting activities.

(b) Farming is not just a business but a way of life. Families may have noneconomic motivations for farming.

(c) Family members often work unpaid on the farm. One survey found that in 1990 over one third of unpaid family workers worked 30 hours or more per week on the farm. ${ }^{57}$

(d) Farm visitors may be there for work related purposes, eg a shearer or a stock agent, or for non work related purposes, eg a duck shooter.

(e) As illustrated throughout this paper farms contain a variety of hazards.

56 It is acknowledged that difficulty will arise over a definition of farming. Certainly it will include livestock management and also cropping and horticulture. The implication is that any changes will effect farmers and growers. The author, submits that forestry would not be included in the definition.

57 Houghton R.M, Wilson A.G, University of Otago Consulting Group, Dunedin, "Injury to Farmers and Farm Workers", Community Networks Study: Working Paper 1, presented to Accident Rehabilitation and Compensation Insurance Corporation, June 1993, page 31. 
(f) Farmers undertake a wide variety of tasks, often in poor weather and in isolated situations.

(g) Farmers work long hours, typically seven days a week, increasing their exposure to hazards and the probability of working while fatigued.

(h) While no evidence is provided the author postulates that there is a link between economic pressures on a farm (eg downturn in prices) and the provision of safety equipment.

When all the above factors are looked at as a whole the conclusion is that a farm is a unique workplace.

\section{RECOMMENDATIONS FOR CHANGE}

Statistics show farm health and safety is an important issue, and the survey of Taranaki farmers shows that the HSE Act is not achieving the desired effect. Given that farming is different from other industries it is proposed that there are good arguments for change. Tentative solutions are proposed here.

\section{A Enact the HSE Amendment Bill}

This would solve the negative and undesirable results that have arisen from uncertainty over farmers' duties to visitors. Farmers need not lock their gates to the public resulting in all people being able to enjoy the use of farms. The focus will be on individuals to take responsibility for themselves.

\section{B Further Changes}

The Amendment Bill does not tackle further issues that need to be addressed if farm injuries are to be reduced. One solution is to enact a separate division for farmers within the HSE Act that specifically deals with the farming environment. For example, "all practicable steps" could be replaced with the common law duty to take "reasonable care".

Alternatively, farmers could be exempt from the HSE Act altogether and from the single national strategy of 'hazard management.' Instead the focus could be on community-driven programmes that offer practical advice on how to minimise the risk of injury. ${ }^{58}$ This is suggested because it is recognised that there are difficulties in drafting clauses that will effectively result in primary protection from harm. The common law. would still apply and so farmers would not be totally exempt from hazard management duties. ${ }^{59}$ It must also be recognised that farmers are busy people often working in

58 It cannot be denied that there is always going to be a risk of injury on a farm.

59 Above n 25. 
isolated areas and therefore will need help in implementing any changes or receiving any advice. ${ }^{60}$ Ultimately programmes must involve education of farmers by farmers. ${ }^{61}$ Any strategy will have to take account of three different populations, the working farm population, the children and young adults population and the recreational group.

60 Not to mention financial help. One questionnaire participant stated that he or she would have a hazard management plan if OSH paid for it and came and implemented it on the farm.

61 Or at least by those who have had farm experience. 


\section{CONCLUSION}

The responsibilities created under the HSE Act are not entirely unfamiliar but the approach and requirements are certainly unprecedented in the farming industry. The HSE Act specifies that "all practicable steps" must be taken to ensure the prevention of harm to people, whether employees or not, on the farm. It is now over four years since the HSE Act's implementation. The questionnaire results show that farmers have yet to fully embrace the HSE Act. The evidence indicates that this is because the HSE Act is difficult to adapt to a farming environment. 